\title{
Intravenous pulsed vs oral cyclophosphamide therapy in steroid dependent nephrotic syndrome
}

\author{
S Abeyagunawardena ${ }^{1}$, A H H M Jayaweera ${ }^{2}$, R S Thalgahagoda $^{2}$, U I $\operatorname{Karunadasa}^{2}$, $\mathbf{A}$ S \\ Abeyagunawardena ${ }^{2}$
}

Sri Lanka Journal of Child Health, 2017; 46(4): 317-321

\begin{abstract}
Background: No consensus exists concerning dose and route of administration of cyclophosphamide (CYC) in steroid-dependant nephrotic syndrome (SDNS).
\end{abstract}

Objective: To compare the outcome of children with SDNS treated with either intravenous (IV) or oral CYC in a single centre in Sri Lanka by reviewing data from 2002 to 2011.

Method: One hundred and twenty seven children with SDNS with evidence of steroid toxicity received either oral or IV cyclophosphamide. Seventy two received IV cyclophosphamide in a dose of $500 \mathrm{mg} / \mathrm{m}^{2}$ monthly for 6 months, and 55 received oral CYC in a dose of $3 \mathrm{mg} / \mathrm{kg}$ per day for 8 weeks. In both groups prednisolone was tapered over 6 months in a similar manner. Full blood counts were done weekly during oral treatment and monthly during IV treatment. Patient progress was assessed on a monthly basis for the first year and at 3 monthly intervals thereafter till 5 years.

Results: In the oral CYC group, 4 patients developed bone marrow suppression, 7 had serious infections, 15 had significant alopecia and one child died due to overwhelming sepsis. In the IV group alopecia was seen in 9 patients and one had a serious infection while bone marrow suppression was not seen. At one and 5 year follow ups there was no significant difference in the proportion who suffered a relapse in the 2 groups $(\mathrm{p}>0.05)$

Conclusion: In SDNS, IV cyclophosphamide was as effective as oral CYC in inducing sustained remission and had less side effects and a smaller total dose.

${ }^{1}$ Teaching Hospital Peradeniya, Sri Lanka, ${ }^{2}$ Faculty of Medicine, University of Peradeniya, Sri Lanka

*Correspondence: asiriabey26@gmail.com

(Received on 04 January 2017: Accepted after revision on 17 February 2017)

The authors declare that there are no conflicts of interest

Personal funding was used for the project.

Open Access Article published under the Creative

Commons Attribution CC-BY (cc)
DOI: http://dx.doi.org/10.4038/sljch.v46i4.8377

(Keywords: Oral cyclophosphamide, intravenous pulsed cyclophosphamide, childhood steroid dependent nephrotic syndrome)

\section{Introduction}

Nephrotic syndrome (NS) has an annual incidence of $2-7$ per $100,000^{1}$. It describes the triad of generalised oedema, heavy proteinuria and hypoalbuminaemia ${ }^{2}$. In about $90 \%$ of cases it is a primary glomerular disease. The remainder is caused by systemic disorders like systemic lupus erythematosus, vasculitis, infections, drugs and heavy metals ${ }^{3}$. The peak age of presentation of NS is 2 years, $70-80 \%$ cases occurring in children below 6 years ${ }^{4}$. NS can be classified into secondary, congenital, and idiopathic with idiopathic NS being the most frequent form in children ${ }^{5}$. Approximately $80 \%$ of primary NS patients have minimal change disease histologically. More than $90 \%$ respond to corticosteroid therapy and have a good long term prognosis 6 . Over $70 \%$ of these patients subsequently develop relapses and more than $50 \%$ will progress to frequently relapsing nephrotic syndrome (FRNS) or steroid dependent nephrotic syndrome (SDNS). The majority will eventually enter long term remission without progression to end stage renal disease $e^{7,8}$. Steroid dependency is defined by the International Study for Kidney Diseases in Children as children with FRNS in whom two consecutive relapses, or two of four relapses in any 6 month period, occurred while still on a steroid dose or within 14 days of stopping steroid therapy? Relapses are associated with many acute complications like infections, hypovolaemia, thromboembolism and hypertension ${ }^{10}$. Children with FRNS and SDNS become vulnerable for these complications repeatedly. Each relapse is treated with induction of remission with prednisolone $60 \mathrm{mg} / \mathrm{m}^{2}$ as a single daily dose until remission, followed by $40 \mathrm{mg} / \mathrm{m}^{2} /$ every other day for 28 days ${ }^{11}$. Frequent relapses and steroid dependency exposes these children to multiple courses of high-dose prednisolone placing them at risk of a plethora of significant corticosteroid related side-effects such as hypothalamus-pituitary-adrenal axis suppression, hypertension, Cushing syndrome, obesity, bone disease, growth retardation, posterior lenticular cataracts, pubertal delay and behavioural disturbances $^{12-14}$. 
Present guidelines recommend that the first line of treatment for FRNS and SDNS is maintenance therapy with low dose prednisolone 0.1 $0.6 \mathrm{mg} / \mathrm{kg} /$ on alternate days for a period of 6 months followed by slow tapering ${ }^{2}$. Repeated courses of high dose daily steroids can cause more toxicity than these alternate day regimes ${ }^{15}$. If the prednisolone dose required to maintain stable remission is more than $0.6 \mathrm{mg} / \mathrm{kg} / \mathrm{every}$ other day or if the child develops steroid toxicity, steroid sparing immunosuppressive agents are introduced.

The only immunosuppressive agents which have been demonstrated by randomised controlled trials (RCT) to be effective in maintaining stable remission in FRNS and SDNS are immunomodulating agents (levamisole), alkylating agents (cyclophosphamide, chlorambucil) and calcineurin inhibitors (cyclosporine) ${ }^{16}$. The present practice is to use levamisole followed by alkylating agents first and reserve cyclosporine for patients who relapse frequently while on these agents. Both alkylating agents have been demonstrated to induce a prolonged period of stable remission after discontinuation of the drug whereas both levamisole and cyclosporine are known to result in relapse after cessation of therapy. Of the two alkylating agents which show similar efficacies, cyclophosphamide (CYC) is the most widely used due its lower toxicity profile ${ }^{4}$. However, no consensus exists concerning dose and route of administration of CYC in SDNS.

\section{Objective}

To compare the outcome of children with SDNS treated with either intravenous (IV) or oral CYC in a single centre in Sri Lanka by reviewing data from 2002 to 2011.

\section{Method}

The Professorial Paediatric Unit of the Teaching Hospital Peradeniya is a tertiary referral centre to which most patients with complicated NS are referred. Clinical data of all patients with NS were entered and regularly updated on a computerised data base since 2002 in accordance with the data protection act 1998 and patient confidentiality and the approval of the Research and Ethics Committee of the Faculty of Medicine, University of Peradeniya. This database was maintained throughout by the principal author.

When a patient relapsed more than twice while receiving prednisolone above $1 \mathrm{mg} / \mathrm{kg}$ on alternate days with or without levamisole or when unacceptable side effects were encountered with alternate-day prednisolone and levamisole therapy, they were considered for CYC therapy. The decision to administer oral or IV was made after discussing with parents regarding the potential advantages and disadvantages. The distance to the local healthcare facility and the potential to default treatment due to social circumstances were also taken into consideration.

All such patients considered for CYC therapy received an identical steroid regimen irrespective of the route of administration. The induction of remission was achieved with oral prednisolone prescribed in a dose of $60 \mathrm{mg} / \mathrm{m}^{2}$ daily till remission followed by $40 \mathrm{mg} / \mathrm{m}^{2}$ every other day for 4 weeks and the steroid therapy was tapered over the next four months.

\section{Oral route}

Once the patient entered remission with daily prednisolone, CYC was prescribed orally $3 \mathrm{mg} / \mathrm{kg}$ as a single dose for eight weeks. During oral therapy patients were reviewed and full blood counts were performed weekly focusing on potential side effects and relapse of proteinuria. After completion of CYC therapy patients were reviewed on a monthly basis for the first one year and thereafter at 3 monthly intervals.

\section{Intravenous route}

Intravenous pulses of $\mathrm{CYC}$ were administered at monthly intervals at $500 \mathrm{mg} / \mathrm{m}^{2}$ and were reviewed monthly to monitor for potential side effects and relapse of proteinuria. Thereafter all patients were closely monitored at the renal clinic for first one year with monthly reviews and 3 monthly reviews for the following years.

All parents were trained to test for early morning samples for urine protein excretion by sulphosalicylic acid test and were advised to record it on a daily basis in the patient held record book provided. Urine protein excretion of ++ or more for 3 consecutive days was diagnosed as a relapse.

Patients who had completed 5 years of follow up were included in the study. Patients who were lost to follow up and patients who had a renal histology other than minimal change disease were not considered for analysis. Patients who have had other immune suppressive therapy such as cyclosporine A or mycofenalate mofetil prior to CYC therapy were also excluded. The data of patients were obtained from the database and were analysed for this study using SPSS software version 19.

\section{Results}

One hundred and twenty seven children with SDNS with evidence of steroid toxicity who satisfied the entry criteria during the 10 year period received either oral CYC (55) or intravenous CYC (72). Six other patients were not considered as they were lost to follow up (4 IV route and 2 oral route). Results are summarised in Table 1. 
Table 1: Summary of results $(n=127)$

\begin{tabular}{|c|c|c|}
\hline & $\begin{array}{c}\text { Oral cyclophosphamide therapy } \\
\qquad(n=55)\end{array}$ & $\begin{array}{c}\text { IV cyclophosphamide therapy } \\
\qquad(n=72)\end{array}$ \\
\hline Males & 34 & 49 \\
\hline Females & 21 & 23 \\
\hline Dose & $3 \mathrm{mg} / \mathrm{kg}$ per day & $500 \mathrm{mg} / \mathrm{m}^{2}$ monthly \\
\hline Duration & 8 weeks & 6 months \\
\hline Mean total dosage $(\mathrm{mg} / \mathrm{kg})$ & 168 & 128 (range $110-134$ ) \\
\hline Age range at prescription (years) & $2.6-14.2$ & $2.3-13.5$ \\
\hline Median age (years) & 8.8 & 9.5 \\
\hline Side-effects/ complications & & \\
\hline Bone marrow suppression & 04 & 0 \\
\hline Serious infections & 07 & 01 \\
\hline Alopecia & 15 & 09 \\
\hline Death & 01 & 0 \\
\hline $\begin{array}{l}\text { Number of patients who relapsed } \\
\text { At } 1 \text { year of follow up } \\
\text { At } 5 \text { year of follow up }\end{array}$ & $\begin{array}{l}22(40.0 \%) \\
42(76.4 \%)\end{array}$ & $\begin{array}{l}28(38.9 \%) \\
53(73.6 \%)\end{array}$ \\
\hline Sustained remission & & \\
\hline At 1 year & $33(60.0 \%)$ & $44(61.1 \%)$ \\
\hline At 5 years & $13(23.6 \%)$ & $19(26.4 \%)$ \\
\hline
\end{tabular}

One child died in the oral CYC group due to overwhelming sepsis. At one year of follow up there were no significant differences in the numbers who relapsed in the oral and $\mathrm{CYC}$ groups $(\mathrm{p}>0.05$ comparison of 2 proportions using Standard Error). Similarly, at 5 years of follow up there were no significant differences in the numbers who relapsed in the oral and CYC groups $(p>0.05)$

\section{Discussion}

SDNS is a challenge to the clinician who has to deal with not only the disease and its acute complications but also with the plethora of side effects associated with the treatment that has to be offered. As most children eventually outgrow the disease ${ }^{7,17}$, balancing benefits of various cytotoxic agents against the risks is a matter of considerable importance. Thus, treatment of children with FRNS and SDNS needs to be individualised.

CYC was introduced as a steroid-sparing agent in $1967^{18}$. It exerts its immunosuppressive effect by binding to purine bases and impairing normal DNA transcription $^{19}$. The beneficial effect of CYC in maintaining stable remission even after ceasing therapy in SDNS is well established by randomised controlled trials.

However, like all cytotoxic medications, CYC gives rise to several adverse effects causing long term morbidity. Short term side effects include haemorrhagic cystitis, leucopenia, infections and temporary alopecia and the long term side effects include gonadal toxicity and greater risk of malignancy. The risk of gonadal toxicity is more commonly seen in boys and increases if CYC is administered during the peri-pubertal period. Low sperm counts and future risk of malignancies are related to a cumulative dose exceeding $300 \mathrm{mg} / \mathrm{kg}^{20}$.

The best way to administer CYC minimising the potentially harmful side effects while maintaining its therapeutic benefits is yet to be established. Current practice is to give oral CYC $3 \mathrm{mg} / \mathrm{kg} /$ day as a single dose for 8 weeks along with a tapering course of alternate day prednisolone which can be discontinued. The cumulative dose of oral course comes to $168 \mathrm{mg} / \mathrm{kg}$. A second course of CYC can be given after a period of one year if children continue to relapse. Over $80 \%$ of patients remained in long-term remission after a second course, off all treatment or on low-dose every other day prednisolone in one study. This would come to a cumulative dose of $336 \mathrm{mg} / \mathrm{kg}$ which exceeds the safe range of $300 \mathrm{mg} / \mathrm{kg}$.

This study reveals that there is no difference in terms of efficacy in maintaining sustained remission between intravenous $\mathrm{CYC}$ and oral CYC in SDNS. However, the serious side effects often associated with CYC were not observed in the group treated IV compared to the group treated orally with CYC.

Furthermore, the cumulative dose of the oral course is $168 \mathrm{mg} / \mathrm{kg}$ and that of the IV course remained between $110-134 \mathrm{mg} / \mathrm{kg}$. This would allow a second course to be repeated if necessary via the IV route while maintaining the cumulative dose below the toxic threshold of $300 \mathrm{mg} / \mathrm{kg}$. Moreover, intravenous therapy is more reliable when considering noncompliant patients. 
Intravenous pulsed vs oral cyclophosphamide therapy... Sri Lanka Journal of Child Health, 2017; 46(4): $317-321$

\section{Conclusions}

In SDNS, IV cyclophosphamide was as effective as oral CYC in inducing sustained remission and had less side effects and a smaller total dose.

\section{References}

1. Eddy A, Symons J. Nephrotic syndrome in childhood. Lancet 2003; 362(9384):629-39. https://doi.org/10.1016/S01406736(03)141840

2. British Association for Paediatric Nephrology and Research Unit, Royal College of Physicians. Consensus statement on management and audit potential for steroid responsive nephrotic syndrome. Report of a Workshop by the British Association for Paediatric Nephrology and Research Unit, Royal College of Physicians. Archives of Disease in Childhood. 1994; 70(2):151-7. https://doi.org/10.1136/adc.70.2.151 PMid: 8129444 PMCid: PMC1029725

3. Schrier R, Ellison D. The oedematous patient: Cardiac failure, cirrhosis and nephrotic Syndrome. In: Schrier R, editor. Manual of Nephrology. Philadelphia: Lippincott Williams \& Wilkins; 2016. p. 1-21.

4. Valentini R, Smoyer W. Nephrotic Syndrome. In: Kher K, Schnaper W, Makker S, editors. Clinical Pediatric Nephrology. CRC Press; 2006.p. 155-85. https://doi.org/10.3109/9780203482308-15

5. Niaudet P. Steroid-sensitive nephrotic syndrome in children. In: Avner ED, Harmon WE, Neasde P, editors. Paediatric Nephrology. Philadelphia: Lippincott Williams and Wilkins; 2004.p.543-56.

6. Trachtman H, Sampson M, Sethna C, Gipson D. Childhood onset nephrotic syndrome. In: Fervenza F, Lin J, Sethi S, Singh A, editors. Core Concepts in Parenchymal Kidney Disease. New York: Springer Science \& Business Media; 2013.p.23-24.

7. Koskimies O, Vilska J, Rapola J, Hallman N. Long-term outcome of primary nephrotic syndrome. Archives of Disease in Childhood 1982; 57(7):544-8.

https://doi.org/10.1136/adc.57.7.544

PMid: 7103547 PMCid: PMC1627702

8. Tarshish P, Tobin JN, Bernstein J, Edelmann JR. Prognostic significance of the early course of minimal change nephrotic syndrome: report of the International Study of Kidney Disease in
Children. Journal of the American Society of Nephrology 1997; 8:769-76.

PMid: 9176846

9. International Study of Kidney Disease in Children. Early identification of frequent relapses among children with minimal change nephrotic syndrome. Journal of Pediatrics 1982; 101: 514-18. https://doi.org/10.1016/S00223476(82)806926

10. Park Shin J. Complications of nephrotic syndrome. Korean Journal of Pediatrics 2011; 54(8):322.

https://doi.org/10.3345/kjp.2011.54.8.322

PMid: 22087198 PMCid: PMC3212701

11. Peco-Antic A. Management of idiopathic nephrotic syndrome in childhood. Srpski Arhiv Za Celokupno Lekarstvo. 2004; 132(910):352-9.

https://doi.org/10.2298/SARH0410352P

PMid: 15794060

12. Grenda R, Webb N. Steroid minimization in paediatric renal transplantation: Early withdrawal or avoidance? Pediatric Transplantation. 2010; 14(8): 961-7. https://doi.org/10.1111/j.13993046.2010.0140 3.X PMid: 20874824

13. Polito CD, Toro R. Delayed pubertal growth spurt in glomerulopathic boys receiving alternate-day prednisone. Child Nephrology and Urology 2016; 12(4):202-7.

14. Hall A, Thorley G, Houtman P. The effects of corticosteroids on behaviour in children with nephrotic syndrome. Pediatric Nephrology 2003; 18(12):1220-3. https://doi.org/10.1007/s00467-003-1295-x PMid: 14577022

15. Mandal A. Texbook of Nephrology for the Asian-Pacific Physicians. 2nd ed. New Delhi: Jaypee; 2004. https://doi.org/10.5005/jp/books/10926

16. Pravitsitthikul N, Willis N, Hodson E, Craig J. Non-corticosteroid immunosuppressive medications for steroid-sensitive nephrotic syndrome in children. Cochrane Database of Systematic Reviews 2013; (10):CD002290. https://doi.org/10.1002/14651858.cd002290.p ub4 https://doi.org/10.1002/14651858.cd002290.p ub4 
Intravenous pulsed vs oral cyclophosphamide therapy... Sri Lanka Journal of Child Health, 2017; 46(4): $317-321$

17. Trompeter R, Hicks J, Lloyd B, White R, Cameron J. Long-term outcome for children with minimal-change nephrotic syndrome. The Lancet 1985; 325(8425):368-70.

https://doi.org/10.1016/S01406736(85)91387$\mathrm{X}$

18. Cucer F, Miron I, Müller R, Iliescu Halitchi C, Mihaila D. Treatment with CYC for steroidresistant nephrotic syndrome in children. Moedica 2010; 5(3):167-70.

19. Kondo N, Takahashi A, Ono K, Ohnishi T. DNA damage induced by alkylating agents and repair pathways. Journal of Nucleic Acids 2010; 2010: 543531.

https://doi.org/10.4061/2010/543531

PMid: 21113301 PMCid: PMC2989456
20. Latta K, von Schnakenburg C, Ehrich J. A meta-analysis of cytotoxic treatment for frequently relapsing nephrotic syndrome in children. Pediatric Nephrology 2001; 16(3):271-82.

https://doi.org/10.1007/s004670000523

PMid: 11322378 